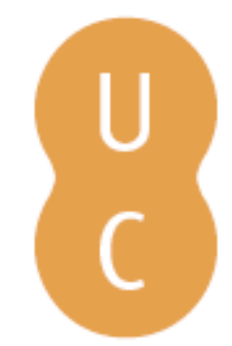

\title{
nombalina
}

\section{Descodificando o De re aedificatoria: usar as novas tecnologias para caracterizar a influência de Alberti na arquitetura clássica em Portugal}

\author{
Autor(es): \\ Duarte, José Pinto; Costa, Eduardo Castro e; Coutinho, Filipe; \\ Figueiredo, Bruno; Krüger, Mário \\ Publicado por: Imprensa da Universidade de Coimbra \\ URL \\ persistente: \\ URI:http://hdl.handle.net/10316.2/36673 \\ DOI: \\ DOI:http://dx.doi.org/10.14195/978-989-26-1015-3_11
}

Accessed : $\quad$ 26-Apr-2023 12:04:27

A navegação consulta e descarregamento dos títulos inseridos nas Bibliotecas Digitais UC Digitalis, UC Pombalina e UC Impactum, pressupõem a aceitação plena e sem reservas dos Termos e Condições de Uso destas Bibliotecas Digitais, disponíveis em https://digitalis.uc.pt/pt-pt/termos.

Conforme exposto nos referidos Termos e Condições de Uso, o descarregamento de títulos de acesso restrito requer uma licença válida de autorização devendo o utilizador aceder ao(s) documento(s) a partir de um endereço de IP da instituição detentora da supramencionada licença.

Ao utilizador é apenas permitido o descarregamento para uso pessoal, pelo que o emprego do(s) título(s) descarregado(s) para outro fim, designadamente comercial, carece de autorização do respetivo autor ou editor da obra.

Na medida em que todas as obras da UC Digitalis se encontram protegidas pelo Código do Direito de Autor e Direitos Conexos e demais legislação aplicável, toda a cópia, parcial ou total, deste documento, nos casos em que é legalmente admitida, deverá conter ou fazer-se acompanhar por este aviso.

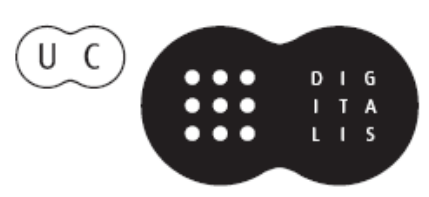


IMPRENSA DA

UNIVERSIDADE

DE COIMBRA

COIMBRA

UNIVERSITY

PRESS

\section{NA GÉNESE DAS RACIONALIDADES MODERNAS II}

Em torno de Alberti e do Humanismo

MÁRIO KRÜGER et alii

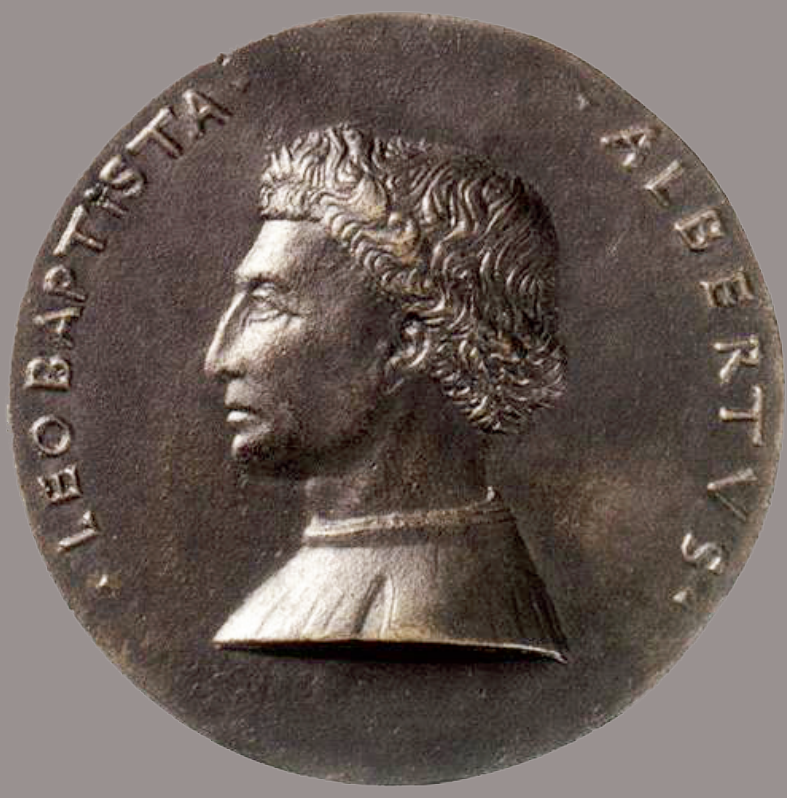


DESCOD I F I CANDO O DE REAEDIFICATORIA:

USAR AS NOVAS TECNOLOGIAS PARA CARACTERIZAR

A INFLUENCIA DE ALBERTI NA ARQUITETURA

CLÁS I CA EM PORTUGAL

José Pinto Duarte, Eduardo Castro e Costa, Filipe Coutinho, Bruno Figueiredo, Mário Krüger

\section{Resumo}

A investigação descrita neste artigo é parte de um projeto que visou a descodificação do tratado de Alberti através da inferência da gramática da forma correspondente, usando depois a estrutura computacional oferecida pelas gramáticas de descrição e da forma para determinar a extensão da tal influência no período da Contra-Reforma em Portugal. O presente artigo concentra-se sobre os fundamentos teóricos que permitem a tradução do texto do tratado de Alberti numa gramática de forma para, em seguida, usá-la para determinar a sua influência na arquitetura renascentista Portuguesa. Teoria da arquitetura; Gramáticas; Automação de projeto; Prototipagem rápida

\section{Résumé}

La recherche décrite dans le présent document fait partie d'un projet visant à décoder le traité en déduisant la grammaire de forme correspondante en utilisant le cadre informatique fourni par les grammaires de déscription et de la forme pour déterminer l'étendue d'une telle influence dans la période de la Contre-Réforme au 
Portugal. Le document se concentrera sur les fondements théoriques qui permettent la traduction du texte du traité de Alberti dans une grammaire de forme et ensuite l'utiliser pour déterminer son influence sur l'architecture portugaise de la Renaissance.

Théorie de 1'architecture; Grammaires; Automatisation de la conception; Prototypage rapide

\begin{abstract}
The research described in this paper is part of a project aimed at decoding the treatise by inferring the corresponding shape grammar using the computational framework provided by description and shape grammars to determine the extent of such an influence in the Counter-Reformation period in Portugal. The paper will concentrate on the theoretical foundations that enable the translation of the text of Alberti's treatise into a shape grammar and then use it in determining its influence on Portuguese Renaissance architecture. Theory of architecture; Grammars; Design automation; Rapid prototyping
\end{abstract}




\section{Introdução}

Este projeto de investigação tem como objetivo compreender o possível impacto cultural do tratado De Re Aedificatoria de Alberti ${ }^{295}$ através do uso de meios computacionais, a fim de determinar as semelhanças do tratado com a prática arquitetónica de raiz clássica em Portugal e nos seus antigos territórios ultramarinos. Na verdade, a influência da teoria Albertiana na arquitetura clássica em Portugal é defendida por alguns autores, mas até agora ninguém foi capaz de determinar a extensão de tal influência. A ideia subjacente ao projeto de investigação foi traduzir o tratado numa gramática descritiva ${ }^{296}$ e numa gramática de forma ${ }^{297}$ e, em seguida, caracterizar a possível influência da obra de Alberti, determinando em que medida estas gramáticas conseguem explicar a génese de edifícios clássicos Portugueses. Esta abordagem segue a ideia de transformações estilísticas $^{298}$ proposta por Knight ${ }^{299}$, segundo a qual a transformação de um estilo noutro pode ser explicada pela alteração da gramática subjacente ao primeiro estilo na gramática subjacente ao segundo. As gramáticas são, assim, propostas como ferramentas complementares a usar pelos historiadores da arquitetura para testar hipóteses levantadas a partir de

295 LEON B. ALBERTI. De Re Aedificatoria (1485). 2 vols., Trad. Latim-Italiano Giovanni Orlandi. Intr. e notas Paolo Portoghesi. Milão, Edizioni il Olifilo, 1966.

LEON B. ALBERTI. De Re Aedificatoria. Editio princeps in facsimile Hans-Karl Lucke, ed. Munich, Prestel verlag, 1975.

LEON B. ALBERTI. On the Art of Building in Ten Books. Trad. Joseph Rykwert, Neil Leach e Robert Tavernor. Cambridge, MA, MIT Press, 1988a.

LEON B. ALBERTI. Profugiorum ab aerumna libri III. Della tranquilità dell'animo. (1441/1442) Ponte, ed. Genova, Casa Editrice Tilgher, 1988b.

296 GEORGE STINY, "A note on the description of designs", em Environment and Planning B: Planning and Design, n. ${ }^{\circ}$ 8, 1981, pp. 257-267.

297 GEORGE STINY \& JAMES GIPS, "Shape Grammars and the Generative Specification of Painting and Sculpture", em C. V. Freiman (ed.), Information Processing, n. ${ }^{\circ}$ 71, Amsterdam, North-Holland, 1972, pp. 1460-1465.

298 'Transformation in Design' no original em inglês, aqui traduzido como transformações estilísticas, atendendo à ideia subjacente de explicar a evolução dos estilos em várias áreas da arte, como por exemplo, na arquitetura, na pintura, na cerâmica e nas artes decorativas, através de transformações gramaticais.

299 TERRY W. KNIGHT, "Transformations of language of design", em Environment and Planning B: Planning and Design, n. ${ }^{\circ}$ 10, 1983, pp. 125-128 (Part 1), pp. 129-154 (Part 2), pp. 155-177(Part 3). 
provas documentais. No decorrer do projeto, as gramáticas desenvolvidas foram implementadas como programas de computador e os modelos digitais por estes gerados foram usados para produzir desenhos e modelos digitais, modelos físicos por prototipagem rápida e modelos de realidade virtual. Estes modelos foram depois incluídos numa exposição itinerante, concebida para descrever e celebrar a obra de Alberti e sua influência na arquitetura Portuguesa. Uma versão inicial deste capítulo foi publicada originalmente em inglês na revista Nexus ${ }^{300}$.

\section{Estado da arte}

Há autores que negam a existência de uma Arquitetura renascentista Portuguesa. Na verdade, Reynaldo dos Santos ${ }^{301}$ sugere que o Renascimento é um estilo estrangeiro que não teve influência sobre o desenvolvimento da arquitetura Portuguesa e Pais da Silva ${ }^{302}$ propõe uma transição direta do estilo Manuelino para o estilo Maneirista, sem reconhecer a existência de um estilo Renascentista. No entanto, mais recentemente, Moreira ${ }^{303}$, ao estudar as encomendas reais entre o estilo Manuelino e o modo romano de construção, foi capaz de identificar cento e cinquenta edifícios que podem ser considerados como pertencentes ao âmbito Renascentista.

Com a ajuda de meios computacionais adequados o projeto Alberti Digital teve como objetivo procurar lançar alguma luz sobre estas questões e desenvolver uma melhor compreensão da arquitetura Renascentista em Portugal. Várias questões podem ser levantadas, contudo a investigação

300 MÁRIO KRÜGER, JOSÉ P. DUARTE, FILIPE COUTINHO, "Decoding De Re Aedificatoria: using grammars to trace Alberti's influence on Portuguese classical architecture", em F. Rodrigues \& K. Williams, Ed., Nexus IV: architecture and mathematics, Fuccechio, Italy, Kim Williams Books, 2002, vol. 13, n. ${ }^{\circ}$ 1, 2011, pp. 171-182.

301 REINALDO SANTOS, Oito séculos de Arte Portuguesa. 3 Vols. Lisboa, Empresa Nacional de Publicidade, Vol. II, 1968-1970, p. 175.

302 J. H. PAIS DA SILVA, Páginas de História de Arte. 2 vols. Lisboa, Ed. Estampa, 1986, p. 109.

303 R. MOREIRA, "Arquitetura: Renascimento e Classicismo", em P. Pereira, ed., História da Arte Portuguesa, vol. II. Lisboa, Circulo dos Leitores, 1995, pp. 302-375. 
centrou-se no uso das novas tecnologias, nomeadamente a prototipagem rápida e a realidade virtual, mas sobretudo as gramáticas da forma, para clarificar questões com raízes históricas profundas.

De fato, o tratado de Alberti pode ser pensado como um conjunto de algoritmos desenvolvidos com o objetivo de codificar princípios arquitetónicos inteligíveis. Consideremos, por exemplo, o sistema da coluna como proposto no Livro VII, cap. 7 do tratado e, mais especificamente, as proporções da base Jónica 304 .

Neste caso, todas as prescrições proporcionais da base Jónica podem ser transformadas num programa de computador. Na verdade, todas as questões levantadas pelas dimensões e disposição dos elementos de arquitetura, tais como o diâmetro da coluna e as suas proporções, a posição do toro, do dado, das duas escócias e dos anéis, podem ser enquadradas computacionalmente, na medida em que constituem problemas bem definidos e, por conseguinte, descritíveis através de um conjunto de formas e regras de transformação destas formas. Mesmo a base Jónica pode ser pensada como uma consequência de uma forma antecedente, a base Dórica. O mesmo acontece com os edifícios, onde, por exemplo, os edifícios sagrados descritos no Livro VII derivam da basílica romana. Em suma, formas antecedentes e formas consequentes estão profundamente inter-relacionados no quadro teórico definido por Alberti.

Estas formas e transformações da forma podem ser exploradas e desenvolvidas para traduzir as regras estabelecidas no tratado como um sistema computacional, como inicialmente pensado por Stiny 305 e mais recentemente desenvolvido por Duarte ${ }^{306}$, para o estudo das casas de Siza na Malagueira em Portugal, onde as gramáticas são utilizadas para personalizar a habitação em série. Existem precedentes de gramáticas de forma

${ }^{304}$ LEON B. ALBERTI. On the Art of Building in Ten Books. Trad. Joseph Rykwert, Neil Leach e Robert Tavernor. Cambridge, MA, MIT Press, 1988a, pp. 203-204.

305 GEORGE STINY, "Introduction to Shape and Shape Grammars", em Environment and Planning B: Planning and Design n. ${ }^{\circ} 7,1980$, pp. 343-352.

306 JOSÉ P. DUARTE, Customizing Mass Housing: a discursive grammar for Siza's Malagueira houses. Ph.D. Dissertation, Massachusetts Institute of Technology, Cambridge, MA, 2001. 
desenvolvidas para codificar algoritmos especificados em tratados de arquitetura. Por exemplo, a gramática desenvolvida por Andrew Li (2002) codifica as regras descritas num tratado Chinês do século XII. Existem também precedentes de programas de computador desenvolvidos a partir de algoritmos definidos em tratados de arquitetura clássica como, por exemplo, o trabalho preliminar desenvolvido no contexto de uma disciplina de programação para estudantes de arquitetura. Nesta disciplina, após leitura do tratado "Dez Livros de Arquitetura" de Vitrúvio, alguns alunos traduziram o conhecimento arquitetónico descrito no capítulo dos teatros, num programa de computador. Este programa podia ser usado para gerar modelos digitais tridimensionais de teatros, tendo em consideração o número de espectadores. Finalmente, estes modelos, foram utilizados na produção de modelos físicos por prototipagem rápida. Este trabalho incluiu um passo intermediário para traduzir as instruções verbais estabelecidas no tratado num modelo paramétrico antes de escrever o programa de computador em Autolisp, a linguagem de programação elementar do Autocad. Uma metodologia semelhante foi utilizada no projeto Alberti Digital para traduzir as instruções de Alberti para a conceção de edifícios clássicos em programas de computador, posteriormente usados na produção de modelos digitais e de modelos físicos. No entanto, o formalismo computacional primordial usado no projeto Alberti Digital para traduzir as descrições textuais contidas no tratado De re aedificatoria num programa de computador foi uma gramática e não um modelo paramétrico. A razão desta escolha foi dupla. A primeira razão foi a capacidade superior das gramáticas para codificar instruções complexas devido à possibilidade de combinar descrição e forma em gramáticas compostas. A segunda razão foi a capacidade destas para descrever como gerar uma solução de projeto por aplicação sequencial de regras, uma característica importante, dados os objetivos didáticos e pedagógicos do projeto e a intenção de determinar em que medida as regras de Alberti seriam capazes de gerar a arquitetura de raiz clássica construída no espaço do antigo império Português.

Seguindo esta estrutura, a arquitetura Renascentista em Portugal e nos seus antigos territórios ultramarinos do Brasil e da Índia pode ser pensada como uma espécie de personalização das regras estabelecidas 
no tratado de Alberti. Essa é a nossa hipótese fundamental para o desenvolvimento de uma gramática da forma da arquitetura Renascentista em Portugal a partir da gramática da tratado original. O trabalho apresentado desenvolveu-se em seis etapas básicas:

1. Inferir uma gramática da forma a partir do texto do tratado, seguindo um procedimento semelhante ao usado por $\mathrm{Li}^{307}$;

2. Estruturar, testar e implementar essa gramática com os edifícios projetados por Alberti como executado por Duarte 308 ;

3. Reconhecer as transformações operadas na gramática do tratado de Alberti, convertendo-a na gramática dos edifícios por ele projetados, como sugerido 309 e observado ${ }^{310}$ por Krüger, de um modo semelhante ao proposto por Knight ${ }^{311}$;

4. Compreender as transformações operadas nesses dois conjuntos de regras e formas para produzir a arquitetura Renascentista em Portugal e nos territórios ultramarinos, como reconhecido por Carita ${ }^{312}$;

5. Implementar um software educacional para a geração e fabricação interativa de projetos, ligando as gramáticas da forma à prototipagem rápida, seguindo o modelo proposto por Duarte e Wang ${ }^{313}$;

6. Organizar uma exposição, a fim de divulgar amplamente os resultados obtidos.

307 ANDREW I. LI, "Algorithmic architecture in twelfth-century China: the yingzao fashi", em F. Rodrigues \& K. Williams, Ed., Nexus IV: architecture and mathematics, Fuccechio, Italy, Kim Williams Books, 2002, pp. 141-150.

308 JOSÉ P. DUARTE, "Towards the Mass Customization of Housing: the grammar of Siza's houses at Malagueira", em Environment and Planning B: Planning and Design, vol. 32, n. ${ }^{\circ}$ 3, 2005, pp. 347-380.

309 MÁRIO KRÜGER, "A Recepção Da Arte Edificatória", em Leon Battista Alberti, Da Arte Edificatória, Lisboa, Fundação Calouste Gulbenkian, 2011, pp. 75-129.

310 LEON B. ALBERTI, Da Arte Edificatória, Trad. Arnaldo Espírito Santo, intr. e notas Mário Júlio Teixeira Krüger. Lisboa, Fundação Calouste Gulbenkian, 2011.

311 TERRY W. KNIGHT, Transformations in Design: a Formal Approach to Stylistic Change and Innovation in the Visual Arts, Cambridge, England, Cambridge University Press, 1994.

312 HÉLDER CARITA, Arquitetura Indo-Portuguesa na Região de Cochim e Keral, Lisboa, Fundação Oriente/Transbooks.com, 2008.

313 JOSÉ P. DUARTE, \& YUFEI WANG, "Automatic Generation and Fabrication of Designs", em Automation in Construction, Vol. 11, n. ${ }^{\circ} 3,2002$, pp. 291-302, Elsevier Science. 
Finalmente, uma nota sobre o resultado final do projeto. Rykwert e Angel ${ }^{314}$ produziram antes uma exposição notável sobre a obra de Alberti, a qual incluía o uso de modelos digitais e modelos físicos tridimensionais em madeira, mas sem usar qualquer tipo de automação. Em certa medida, o projeto Alberti Digital pode ser pensado como um desenvolvimento desta pesquisa inicial, criado com o objetivo de tornar as regras de Alberti operativas, entendendo-as como uma forma de computação para compreender as transformações arquitetónicas que ocorreram em Portugal durante a Contra-Reforma. Neste sentido, a tradição e a inovação estão unidas pela ideia de que a computação pode desempenhar um papel importante na compreensão de arquitetura Renascentista em Portugal e, portanto, lançar alguma luz sobre as questões controversas mencionadas no início deste artigo, levantadas independentemente por Santos, Silva e Moreira.

\section{Metodologia}

O tratado de Alberti é um dos tratados de arquitetura mais influentes do Renascimento. No século XVI, o rei D. João III encomenda a sua tradução para o Português. Perdidos os exemplares desta tradução, a sua influência na arquitetura Portuguesa permanece indefinida, sendo objeto de debate entre os estudiosos. A recente tradução do tratado de Alberti do Latim para o Português forneceu a base para determinar a extensão de tal influência e, portanto, lançar uma nova luz sobre o debate.

O objetivo do projeto foi, portanto, ajudar a compreender a eventual influência cultural do tratado de Alberti sobre a arquitetura clássica Portuguesa e a ideia foi usar a estrutura computacional fornecida pelas gramáticas de descrição e da forma para determinar a extensão de tal influência no período da Contra-Reforma. A metodologia para alcançar este objetivo incluiu as seguintes tarefas:

314 J. RYKWERT \& A. ANGEL, Leon Battista Alberti. Catallogo della mostra Palazzo Te. Milão, Olivetti/Electa, 1994. 
a. descodificar o tratado e inferir a gramática da forma correspondente;

b. comparar a gramática do tratado com os edifícios projetados por Alberti;

c. traçar a influência do tratado sobre arquitetura Portuguesa mapeando as gramáticas de um tipo de edifício, em Portugal e seus territórios ultramarinos, para transformações sucessivas da gramática inicial do tratado para o mesmo tipo de edifício;

d. traçar os impactos do tratado sobre a teoria, prática e ensino da arquitetura, mapeando as gramáticas subjacentes a outros trabalhos teóricos e construídos para transformações subsequentes da gramática inicial;

e. divulgar os resultados da investigação entre os estudiosos e o público em geral através da montagem de uma exposição visualmente atraente usando meios digitais.

A gramática é composta por um conjunto de regras de substituição que se aplicam de forma recursiva a uma afirmação inicial para produzir uma afirmação final. Na gramáticas de descrição, as afirmações são descrições simbólicas, enquanto que nas gramáticas da forma, elas consistem em descrições das formas.

A relação entre as gramáticas de descrição e as gramáticas da forma é tal que, para cada regra da forma existe uma regra de descrição correspondente e, portanto, é possível traduzir uma gramática descritiva numa gramática da forma. Stiny e Mitchell 315 mostraram que uma gramática pode descrever a estrutura formal e funcional de um determinado estilo arquitetónico (valor descritivo), explicar como sintetizar novos exemplares do estilo (valor sintético) e determinar se um novo exemplar pertence ao mesmo estilo (valor analítico). Estes valores das gramáticas foram essenciais para o desenvolvimento da investigação.

$O$ tratado de Alberti pode ser pensado como um conjunto de algoritmos que explicam como desenhar edifícios de acordo com os cânones da arquitetura clássica. O objetivo do projeto Alberti Digital foi converter os

315 GEORGE STINY \& WILLIAM MITCHELL, "The Palladian Grammar", em Environment and Planning B: Planning and Design n. ${ }^{\circ}$ 5, 1978a, pp. 5-18. 
algoritmos do tratado numa gramática de descrição, em seguida, numa gramática da forma e, finalmente, num programa de computador. Este objetivo foi alcançado completando as seguintes quatro tarefas:

Tarefa 1, "compreender o tratado", visou a compreensão profunda do tratado através do desenho de objetos de acordo com as suas regras usando técnicas de desenho assistido por computador, sem automatismos e, em seguida, da produção dos modelos 3D correspondentes, utilizando técnicas de prototipagem rápida;

Tarefa 2, "inferir a gramática", visou o desenvolvimento da gramática, ganhando assim uma visão sobre a estrutura formal da interpretação Albertiana da arquitetura clássica;

Tarefa 3, "implementar a gramática", consistiu na escrita de um programa de computador que codifica a gramática, permitindo a derivação automática ou interactiva de soluções dentro da linguagem por ela definida; e

Tarefa 4, "comparar a gramática do tratado," visou comparar a gramática do tratado com edifícios reais projetados por Alberti e depois com edifícios clássicos Portugueses para determinar em que medida coincidiam.

Knight ${ }^{316}$ demonstrou que a transição de um dado estilo num estilo diferente, mas relacionado, pode ser explicada pela transformação da gramática subjacente ao primeiro estilo na gramática subjacente ao segundo, através da adição, subtração e transformação de regras. O objetivo do projeto foi rastrear a influência do tratado de Alberti na arquitetura Portuguesa da Contra-Reforma, determinando em que medida a geração de edifícios deste período pode ser explicada por transformação da gramática do tratado. Nesta fase, a investigação concentrou-se num tipo de edifício, nomeadamente nas igrejas porque estas representavam

316 TERRY W. KNIGHT, "Transformations of language of design", em Environment and Planning B: Planning and Design, n. ${ }^{\circ}$ 10, 1983, pp. 125-128 (Part 1), pp. 129-154 (Part 2), pp. 155-177 (Part 3). 
o programa funcional mais amplamente construído e estudado. Este aspeto era importante por aumentar as probabilidades de haver edifícios e elementos de suporte (desenhos, gravuras, descrições, etc.) que tivessem resistido ao passar do tempo em número suficiente, bem como trabalho académico relevante para tornar o projeto Alberti Digital viável.

Tradicionalmente, a história da arquitetura baseia-se no estudo de fontes documentais para traçar influências entre obras teóricas e construídas. Esta abordagem é limitada quando não há provas documentais suficientes. Uma abordagem alternativa é estudar as propriedades inerentes dos artefactos de arquitetura para determinar as semelhanças e diferenças entre eles. Isto é particularmente importante no caso de propriedades funcionais e espaciais, as quais são muitas vezes ignoradas pelos historiadores, principalmente devido à falta de uma metodologia rigorosa para descrever e comparar tais propriedades. É uma metodologia assim que as gramáticas podem proporcionar ao fornecer o aparato técnico necessário para o efeito. O projeto Alberti Digital teve, pois, como objetivo combinar estas duas abordagens, ou seja, usar uma abordagem cultural para rastrear possíveis influências do tratado de Alberti sobre a arquitetura que se seguiu e, em seguida, usar gramáticas para confirmar tal influência, concentrando-se em aspetos funcionais e espaciais. Além disso, esperava-se que este esforço pudesse constituir uma base para um inquérito sobre a utilidade de gramáticas e ferramentas computacionais para o ensino e prática da arquitetura de hoje. Um dos objetivos principais do projeto foi, portanto, apurar os impactos do tratado de Alberti na teoria, prática e ensino de arquitetura através da combinação de abordagens culturais e computacionais.

Além disso, Alberti reconhece que as combinações isoladas de elementos arquitetónicos não tem sentido, mas se forem combinados, podem produzir algo bem concebido, gracioso e conveniente:

"Eu estou acostumado, sobretudo à noite, quando a agitação da minha alma me enche de preocupações e eu procuro alívio para essas preocupações amargas e tristes pensamentos, pensando e construindo na minha mente alguma máquina inédita para mover e carregar pesos, tornando possível a criação de coisas grandes e maravilhosas. E às vezes acontece 
que eu não só acalmo a agitação da minha alma, mas invento algo excelente e digno de ser lembrado. E noutras vezes, em vez de prosseguir estes tipos de pensamentos, componho na minha mente e construo um edifício bem concebido, organizando várias ordens e números de colunas com diversos capitéis e bases incomuns, e a ligação destes com cornijas e placas de mármore, que dão toda a comodidade e uma nova graça".317

Esta afirmação sugere fortemente que a abordagem Albertiana à geração de formas arquitetónicas é capaz de ser capturada por uma gramática da forma, o que apoiou o nosso objetivo de desenvolver uma tal gramática dentro do contexto Português da Contra-Reforma.

\section{Tarefa 1: Compreender o tratado}

Esta foi uma tarefa preparatória necessária para a obtenção de uma compreensão profunda do tratado. Ela teve três objetivos. O primeiro objetivo foi fazer uma leitura geral dos seus 10 livros (capítulos), a fim de descrever todas as características capazes de terem um conteúdo gramatical visual explícito. O segundo objetivo foi transformar estas instruções explícitas em descrições visuais que servissem de base à construção de uma gramática da forma, tais como:

a) fazer uma clara distinção entre lineamentos, materiais e construção;

b) descrever as principais diferenças entre os edifícios públicos e privados;

c) compreender o ornamento de edifícios sagrados, seculares e privados.

317 Traduzido do inglês: "I am accustomed, most of all at night, when the agitation of my soul fills me with cares, and I seek relief from these bitter worries and sad thoughts, to think about and construct in my mind some unheard-of machine to move and carry weights, making it possible to create great and wonderful things. And sometimes it happens that I not only calm the agitation of my soul, but invent something excellent and worthy of being remembered. And at other times, instead of pursuing these kinds of thoughts, I compose in my mind and construct some well-designed building, arranging various orders and numbers of columns with diverse capitals and unusual bases, and linking these with cornices and marble plaques which give the whole convenience, and a new grace."

Leon B. Alberti, Profugiorum ab aerumna libri III. Della tranquilità dell'animo. (1441/1442) Ponte, ed., Genova, Casa Editrice Tilgher: Volume III, 1988b, pp. 114-115. 
O terceiro objetivo foi estabelecer as principais diretrizes para o desenvolvimento visual do sistema da coluna de Alberti, bem como as estratégias de projeto globais para os edifícios públicos e privados e também para os sagrados e profanos.

O objetivo final foi assim identificar as principais linhas de investigação necessárias para transformar os lineamentos do tratado em algoritmos capazes de fornecer um configuração explícita das ideias de Alberti.

Esta tarefa foi desenvolvida em duas fases ou sub-tarefas. A primeira envolveu todos os pesquisadores no estudo e uma reflexão sobre o tratado. A segunda originou modelos de desenho dos tipos de edifícios.

\section{Estudar o tratado original e suas traduções em Português e Inglês}

A inspiração seminal para este trabalho foi a tradução do tratado de Alberti para Português. Como tal, parte do trabalho de coleta de informações foi feito junto com o trabalho de tradução do Latim para o Português. Assim, esta tarefa inicial concentrou-se no estudo do tratado original em latim, das imagens mais tarde desenvolvidas para ilustrar a tradução em Inglês, com base na edição florentina do tratado efetuada por Cosimo Bartoli em 1550 e na edição em Português por Mário Krüger e Arnaldo Espírito Santo, publicada em 2011 pela Fundação Calouste Gulbenkian.

\section{Criar modelos 2D e 3D dos artefatos arquitetónicos descritos no tratado}

Uma forma eficaz de entender o tratado foi criar desenhos 2D e modelos 3D digitais dos elementos descritos por Alberti, incluindo o sistema de coluna e edifícios completos, seguindo os respetivos algoritmos. Tal entendimento ajudou a clarificar os algoritmos e a preparar a informação necessária para escrever as gramáticas correspondentes nas tarefas seguintes. Os desenhos e modelos constituíram material de visualização importante para facilitar a análise e comparação dos edifícios descritos 
e projetados por Alberti com aqueles projetados e construídos dentro do espaço do antigo império Português.

Estas subtarefas encontram-se representadas na Figura 1.

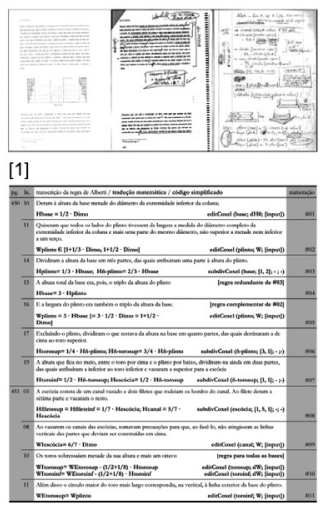

[2]
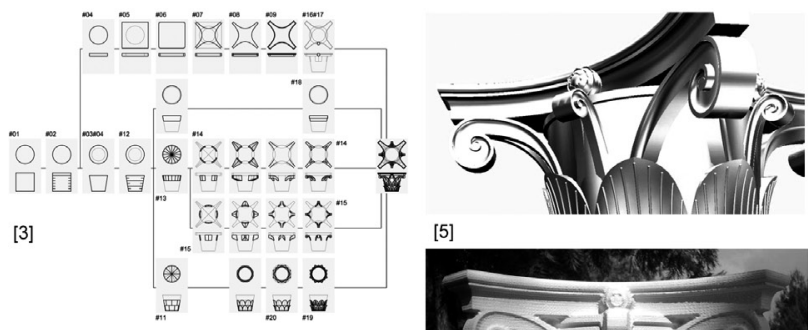

[5]
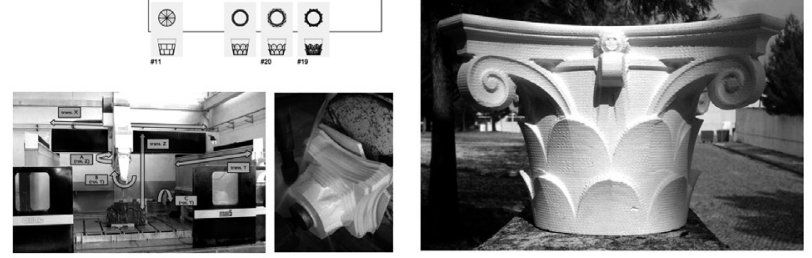

[6]

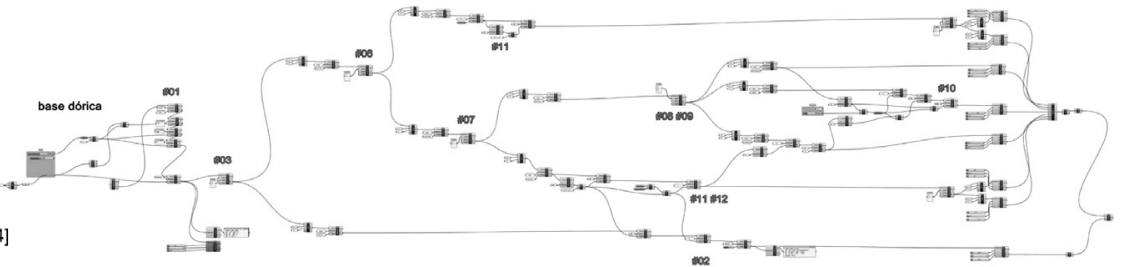

Fig.1 - Conjunto de imagens ilustrando as fases sucessivas de tradução do texto do tratado (1), em esquemas sintetizando os passos dos respetivos algoritmos (2), em diagramas visuais de transformação sucessiva da forma (3), em instruções de programação linguagem visual em Grasshopper (4), em modelos digitais obtidos a partir destes programas (5) e em modelos físico produzidos por fresagem por controlo numérico (6).

\section{Tarefa 2: Inferir a gramática}

\section{A gramática correspondente ao sistema da coluna (columnatio)}

O tratado descreve os algoritmos a seguir no projeto de edifícios de acordo com a interpretação de Alberti da arquitetura clássica. Esta tarefa 
consistiu na tradução do texto do tratado de Alberti em gramáticas de descrição e da forma, o que exigiu extrair e codificar as regras contidas nos algoritmos em tais formatos gramaticais.

A investigação concentrou-se assim, por um lado, no desenvolvimento de uma gramática do sistema da coluna 318 e, por outro, no desenvolvimento de uma gramática para um tipo de edifício escolhido, nomeadamente, os templos ou igrejas 319 .

O sistema da coluna, ou columnatio na terminologia original de Alberti, frequentemente designado por ordens clássicas, estabelece um sistema complexo de relações entre as diversas partes e o todo dos edifícios, de acordo com um sistema de proporções predeterminadas.

As várias partes que compõem o sistema de coluna são símbolos da uma linguagem formal mais alargada. Esta tarefa visou descobrir as relações entre a língua latina (língua original do tratado) e a forma como Alberti define os cânones da sua interpretação das ordens clássicas no Livro VII. A metodologia original do projeto previa, primeiro, escrever o texto no formato de uma gramática de descrição e, em seguida, escrever a gramática da forma correspondente, exteriorizando assim os algoritmos subjacentes ao tratado de Alberti. Contudo, com o desenrolar do projeto, acabou por verificar-se ser mais adequado traduzir sucessivamente o texto original do tratado em diagramas sucessivos, mais textuais no início e sucessivamente mais visuais, até o conseguir converter no final num conjunto de instruções recursivas com o formato das gramáticas da forma (Fig. 1).

A geração de um capitel de acordo com a gramática do sistema da coluna encontra-se representada na Figura 2 e modelos físicos de elementos deste sistema produzidos por prototipagem rápida na Figura 3.

318 FILIPE COUTINHO. Gramática da Forma da Sistematização da Coluna de Alberti. Tese de Doutoramento, Coimbra, Departamento de Arquitetura, Faculdade de Ciências e Tecnologia, Universidade de Coimbra, 2014.

319 BRUNO FIGUEIREDO. Descodificação da De re aedificatoria de Alberti: Uma abordagem computacional à análise e geração de arquitetura clássica. Tese de Doutoramento, Guimarães, Escola de Arquitetura, Universidade do Minho, em elaboração. 

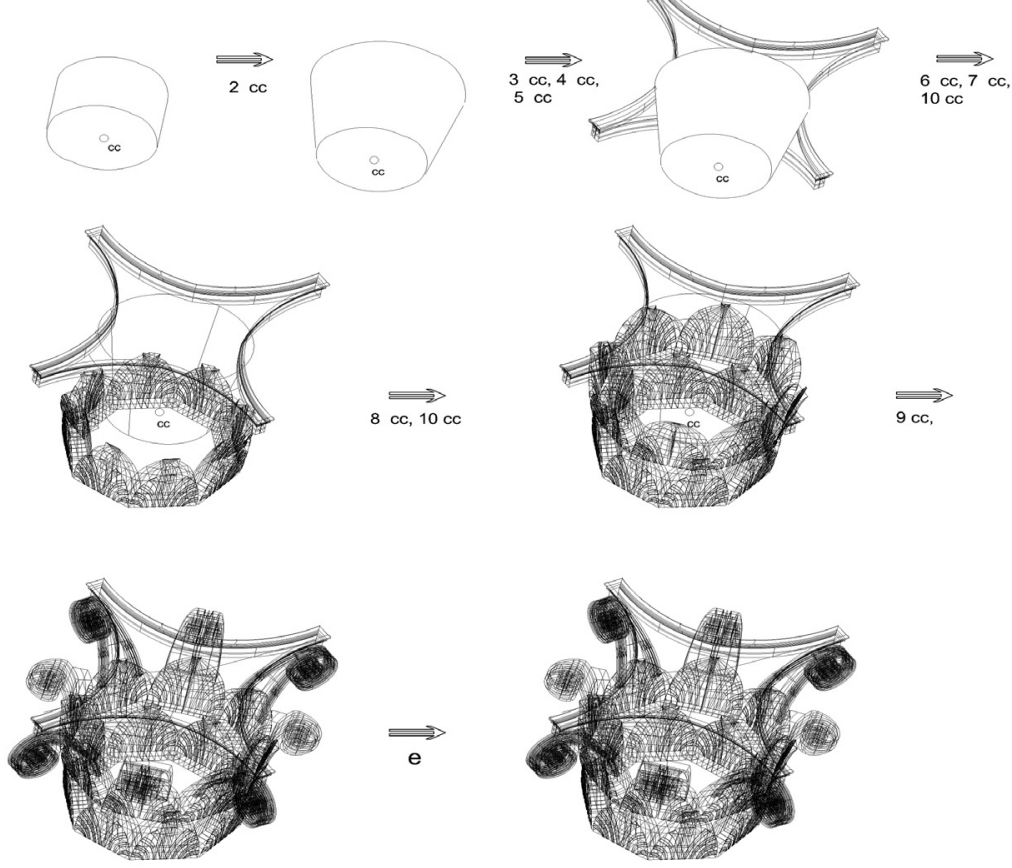

Fig. 2 - Geração de um capitel coríntio de acordo com a gramática do sistema da coluna.

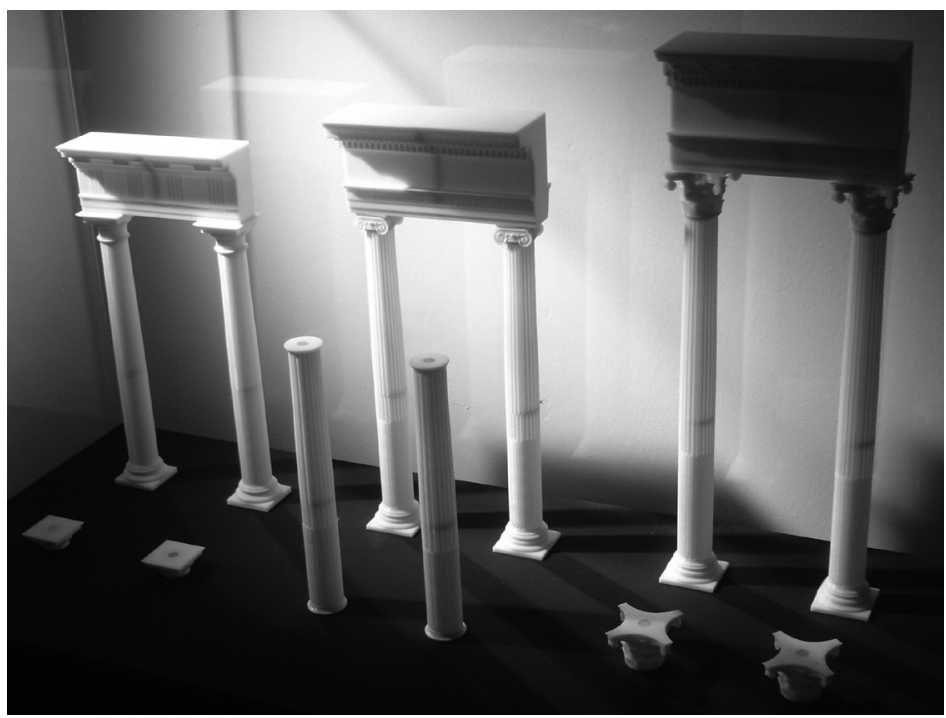

Fig. 3 - Modelos físicos de elementos do sistema da coluna gerados de acordo com a respetiva gramática e produzidos por prototipagem rápida. 


\section{A gramática correspondente a um tipo de edifício em particular (templos)}

O tratado também estabelece regras muito claras para projetar edifícios completos, especialmente aqueles descritos no Livro VII, no Livro VIII (O ornamento de edifícios sagrados e públicos) e no Livro IX (O ornamento de edifícios privados). No planeamento da investigação, previu-se eleger um determinado tipo de construção como caso de estudo e, em seguida, desenvolver a gramática correspondente, utilizando o mesmo método mencionado acima para o sistema da coluna. O conhecimento prévio do tratado e da arquitetura construída da época permitiu desde logo identificar os templos, ou seja as igrejas, como o tipo de edifício mais adequado ao estudo que se pretendia desenvolver, devido ao elevado número de exemplares que foram construídos e subsistiram até aos nossos dias. A gramática desenvolvida codifica as regras para a geração das plantas e das fachadas, de acordo com o sistema de proporções definido pelo sistema de coluna. A aplicação das regras na geração de uma igreja é ilustrada na Figura 4 e modelos digitais de várias igrejas gerados de acordo com a gramática, constituindo parte do universo de soluções são mostrados na Figura 5.

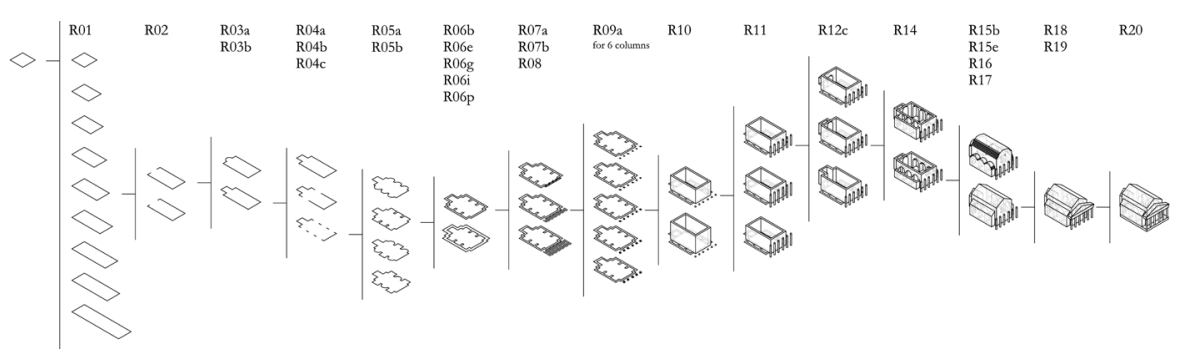

Fig. 4 - Aplicação das regras da gramática dos templos para gerar uma igreja em particular. 


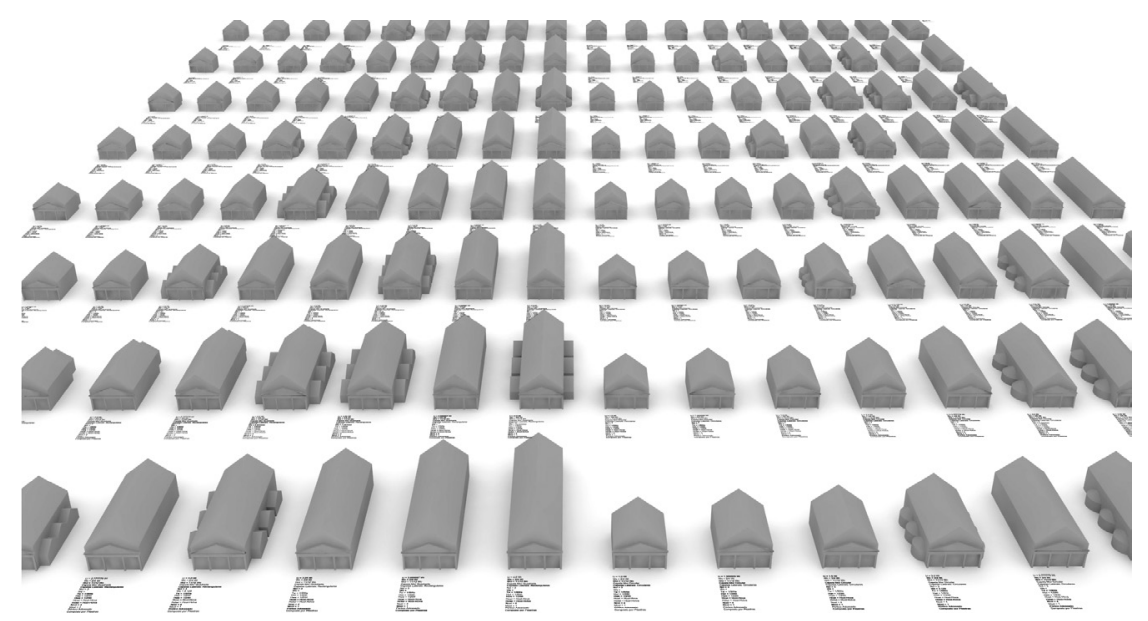

Fig. 5 - Modelos digitais de igrejas gerados de acordo com a gramática, constituindo parte do universo de soluções.

Escrever as regras contidas no tratado em formato gramatical permitiu sistematizá-las de tal forma que tornou possível verificar em que medida Alberti as seguiu nos edifícios por si concebidos, facilitando simultaneamente a sua implementação informática. Estas gramáticas foram assim utilizadas, na Tarefa 3, para comparar as regras estabelecidas por Alberti no tratado com aquelas que ele seguiu na conceção de edifícios reais e, na Tarefa 4, para desenvolver a implementação informática.

\section{Desenvolvimento de representações digitais 2D e 3D}

O objetivo desta subtarefa foi construir representações digitais $2 \mathrm{D}$ e 3D detalhadas a partir, tanto dos resultados gerados pelas implementações informáticas das gramáticas, como de outras fontes de informação, incluindo ilustrações do tratado e plantas e alçados da obra construída de Alberti e de edifícios portugueses por ele influenciados. Esta subtarefa abrangeu o desenvolvimento de desenhos e modelos geométricos, o mapeamento de texturas e a criação de cenas foto-realistas. Algumas das representações digitais foram produzidas manualmente, utilizando o computador sem automatismos, ao passo que outras foram produzidas 
automaticamente usando os vários programas desenvolvidos no decurso do projeto. Posteriormente, os modelos digitais foram usados para produzir modelos físicos através de prototipagem rápida.

\section{Técnicas de prototipagem rápida}

O desenvolvimento de gramáticas permitiu revelar de forma clara as regras codificadas no tratado e a sua implementação informática permitir explorá-las. No Livro I (Lineamenta), Alberti refere-se a desenhos 2D e modelos 3D, como os elementos descritivos do projeto de edifícios. A investigação usou várias tecnologias de ponta baseadas em computador para produzir estes tipos de elementos. O uso de prototipagem rápida permitiu uma visualização tangível dos resultados gerados pelas implementações informáticas e, particularmente, da interpretação de Alberti da arquitetura clássica, facilitando assim a afinação das gramáticas e ampliando os impactos didático-pedagógicos dos resultados da investigação.

\section{Seleção de técnicas de prototipagem rápida}

O objetivo desta subtarefa foi experimentar e selecionar técnicas de prototipagem rápida apropriadas à produção de modelos físicos a partir dos modelos digitais gerados automaticamente pelas implementações informáticas. Algumas das técnicas testadas e utilizadas para o projeto já estavam disponíveis nas instituições participantes no projeto (corte a laser, impressão 3D, fresadoras $\mathrm{CNC}$, etc.), enquanto que outras foram adquiridas no âmbito do projeto para aumentar as capacidades de fabricação durante e além do projeto.

A produção de modelos físicos utilizando técnicas de prototipagem rápida

O objetivo foi estudar e ilustrar as qualidades espaciais e formais da interpretação Albertiana da arquitetura clássica e a sua influência na 
arquitetura Portuguesa no período da Contra-Reforma. Foi assim possível obter uma melhor compreensão da complexidade do pensamento de Alberti sobre a implementação e conceção de edifícios sagrados e profanos, nomeadamente sobre a relação entre o pensamento discursivo e não discursivo. Isto é evidente quando Alberti inventa novos termos para descrever os elementos do sistema de coluna, tais como rudens (rudentura em Português).

O resultado desta tarefa foi um conjunto de modelos físicos e digitais que foram incluídos na exposição no final. Estes modelos foram úteis primeiro para obter uma melhor compreensão do tratado de Alberti e do seu impacto na arquitetura Portuguesa e, depois, para produzir material visualmente atraente para a exposição final, alcançando assim os objetivos didáticos e pedagógicos do projeto ${ }^{320}$.

\section{Tarefa 3: Implementação das gramáticas}

A codificação do tratado em várias gramáticas, combinadas no final, numa única gramática composta, possibilitou a geração completa de sistemas de colunas e de edifícios de acordo com as regras estabelecidas por Alberti. A implementação informática das gramáticas tornou tal geração mais eficiente e permitiu a exploração interativa em tempo real do espaço de soluções de projeto definido pelo tratado.

\section{Seleção do ambiente informático}

Foi necessário escolher a plataforma de computador a utilizar na implementação das gramáticas, isto é, no desenvolvimento dos chamados interpretadores gramaticais. Isto incluiu a escolha do paradigma de

320 EDUARDO CASTRO E COSTA. Modelação Computacional e Materialização Digital de Elementos Clássicos de Arquitetura: Sistematizando a Coluna de Alberti. Tese de mestrado. Lisboa, Faculdade de Arquitetura da Universidade Técnica de Lisboa, 2012. 
implementação e da linguagem de programação. Com base em experiências anteriores de desenvolvimento de interpretadores para gramáticas semelhantes, rapidamente se chegou à conclusão que não seria necessário implementar a propriedade das gramáticas da forma conhecida por "emergência", o que tornou mais fácil e rápido o desenvolvimento da implementação. No final, a escolha do ambiente informático recaiu sobre o Rhinoceros e as linguagens de programação associadas, nomeadamente, o RhinoScript (linguagem de alto nível) e o Grasshopper (linguagem visual). Os critérios utilizados para escolher a linguagem de programação adequada foram o tipo e a complexidade das formas que se pretendiam gerar, por exemplo, a complexidade geométrica do capitel coríntio (Livro VII), bem como a facilidade e celeridade da implementação informática.

\section{Implementando a gramática do sistema da coluna}

Esta tarefa concentrou-se na execução do interpretador para as ordens do sistema da coluna. Na verdade, não foi implementado um interpretador devido: por um lado, à dificuldade e ao tempo exigido para a implementação direta das gramáticas pela inexistência de um ambiente informático adequado e, por outro, à ausência de propriedades de emergência nas gramáticas desenvolvidas. Esta características das gramáticas do tratado permitiu a sua conversão em vários modelos paramétricos, bastante mais fáceis de implementar. No entanto, esta conversão manteve as propriedades descritivas do tratado devido aos objetivos científicos do projeto, nomeadamente, a comparação entre as diversas gramáticas de raíz Albertiana e a explicitação das suas regras por razões didático-pedagógicas.

A execução dos modelos paramétricos tomou em consideração questões de interface com o utilizador, visando maximizar o alcance dos objetivos didático-pedagógico do projeto para tornar mais facilmente apreensíveis as descrições da forma dos objetos arquitetónicos contida no tratado e o complexo sistema de relações formais estabelecidas. 


\section{Implementando a gramática do tipo de edifício}

Esta tarefa concentrou-se no desenvolvimento da implementação informática da gramática para o tipo particular de edifício selecionado como caso de estudo. Tal como acontece com o interpretador da gramática do sistema da coluna, esta implementação tomou em consideração questões de interface com o utilizador para enfatizar e descobrir as relações espaciais entre alçados e plantas, bem como entre as diferentes partes de cada representação 2D.

O resultado destas tarefas foi dois programas de computador, um implementando a gramática do sistema da coluna e o outro a do tipo de edifício selecionado. Estes programas tornaram possível testar e afinar as gramáticas e explorar o universo de soluções definido pelos algoritmos codificados. No final, eles constituiram a base do software educacional que se desejava implementar, o qual foi completado com a conceção de um interface num ambiente de realidade virtual (Fig. 6). Este interface permitiu efetivamente atingir os objetivos didático-pedagógicos do projeto ao possibilitar a interação amigável com os utilizadores e a exploração intuitiva do universo de projeto de Alberti.

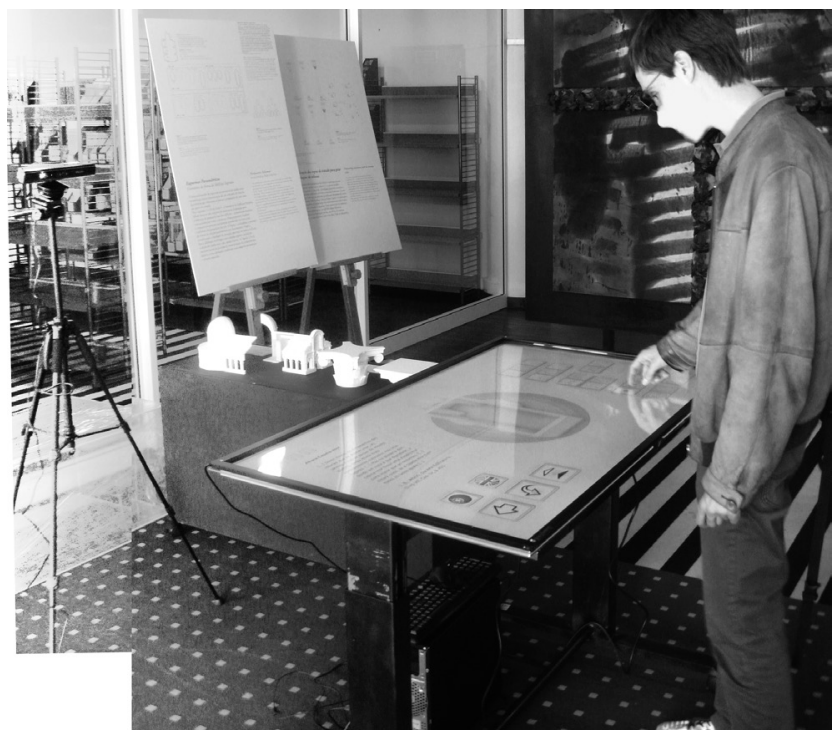

Fig. 6 - Ambiente de realidade virtual desenvolvido para explorar interativamente as regras de Alberti no desenho do sistema da coluna e de templos. 


\section{Comparar a gramática do tratado}

Apesar do tratado estabelecer regras escritas muito claras, a falta de ilustrações na editio princeps sublinha a intenção de Alberti de deixar espaço para a interpretação na conceção de edifícios reais e evitar pôr em risco o rigor das descrições textuais devido a erros aculumados na reprodução de ilustrações de manuscrito para manuscrito. Nesta tarefa, compararam-se edifícios projetados por Alberti com as regras do tratado com a finalidade de identificar possíveis desvios relativamente aos cânones e levantaram hipóteses para explicar a origem de tais desvios. Em seguida compararam os edifícios construídos no espaço do antigo império Português com a obra construída e escrita de Alberti. A base comparativa foi constituída pelas gramáticas subjacentes a cada caso.

\section{Comparar a gramática do tratado com a gramática da obra construída}

Nesta subtarefa, o objetivo foi comparar edifícios reais Albertianos, nomeadamente, a igreja de Santo André em Mântua, o templo Malatestiano em Rimini e o palácio Rucellai em Florença, com as regras do tratado a fim de determinar em que medida as regras do tratado foram respeitadas por Alberti na conceção destes edifícios. Esta tarefa baseou-se na obra "Transformations of Languages of Design" de Terry Knight, já referida, para explicar com rigor os desvios dos cânones tratadistas como alteração, subtração ou adição de regras ao tratado. O resultado foi um mapa das eventuais transformações efetuadas à gramática do tratado para conseguir explicar a geração da obra construída de Alberti. Este mapa identifica claramente que regras foram alteradas, subtraídas ou adicionadas, tendo servido de base para explicar por que motivo tais transformações foram necessárias na conceção de edifícios reais. Este mapa foi depois comparado com os exemplos projetados e construídos no território do antigo império Português. 


\section{Mapeamento das transformações do De re aedificatoria}

O objetivo desta subtarefa foi relacionar as transformações da gramática do tratado identificadas na tarefa anterior com a distribuição geográfica dos casos de estudo selecionados. A ideia foi possibilitar explicar as variações estilísticas encontradas na área geográfica do antigo império como transformações sucessivas da gramática do tratado em gramáticas locais e ligar tais transformações à necessidade de dar resposta a condicionantes práticas de construção ou a características climáticas ou, ainda, a influências arquitetónicas, culturais, ou políticas ou outras influências contextuais. Nesta tarefa, utilizou-se novamente o enquadramento teórico proposto por Terry Knight referido anteriormente, segundo o qual a transformação de um estilo noutro pode ser explicada pela alteração, subtração ou adição de regras à gramática inicial para obter a nova gramática.

O resultado final foi a extensão do mapa de transformações da gramática do tratado na gramática da obra construída de Alberti para incluir a transformação destas gramáticas nas gramáticas do sistema da coluna e das igrejas em Portugal, no Brasil e na Índia no período em estudo. Este mapa foi necessário para compreender a extensão de tais transformações e, desta forma, determinar a possível influência de Alberti na arquitetura do Império português. O mapa tornou ainda possível formular hipóteses sobre a fonte de tais transformações, nomeadamente condicionantes construtivas ou influências contextuais.

\section{Conclusão}

Esta comunicação descreve a metodologia seguida no projeto de investigação Alberti Digital, em que um dos objetivos principais foi, através do uso de meios computacionais, estudar a eventual influência Albertiana na arquitetura de raiz clássica portuguesa. Através do uso deste meios, foi possível traduzir o tratado em gramáticas da forma e, em seguida, determinar o possível grau de tal influência, verificando em que medida tais gramáticas conseguiam descrever a geração de edifícios clássicos 
portugueses. Mais especificamente, verificando o número de regras e parâmetros usados sem alteração na derivação do sistema da coluna e do tipo de edifício selecionado como caso de estudo - templos, isto é, igrejas - foi possível determinar o grau de proximidade aos cânones Albertianos especificados no tratado. Complementarmente, ao descobrir o número de regras que necessitavam de ser alteradas, eliminadas e adicionadas para o efeito, foi possível determinar o grau de desvio do caso Português relativamente aos princípios de Alberti. Atendendo a estes resultados, o uso desta metodologia é proposto em complemento ao uso tradicional de fontes documentais. O argumento é que as gramáticas oferecem um método rigoroso para testar hipóteses levantadas pelo uso de tais métodos tradicionais.

Agradecimentos

O projeto Alberti Digital foi financiado pela Fundação para a Ciência e a Tecnologia (FCT), Portugal, com a bolsa PTDC/AUR-AQI/108274/2008, acolhido pelo Centro de Estudos Sociais da Universidade de Coimbra e coordenado por Mário Krüger. O trabalho de F. Coutinho e B. Figueiredo no projeto foi ainda financiado pela FCT, através das bolsas de doutoramento SFRH/BD/66029/2009 e PTDC/AUR-AQI/108274/2008. Os autores agradecem ainda a T. Knight, G. Stiny e W. J. Mitchell o seu apoio como consultores do projeto. Tristemente, Bill Mitchell faleceu a 11 de junho de 2010, quando o projeto se desenrolava. Agradecemos profundamente o seu apoio e amizade ao longo dos anos, sentindo profundamente falta de ambos. 